\begin{tabular}{|c|c|}
\hline Title & Solid-phase epitaxial film growth and optical properties of a ferroelectric oxide, Sr2Nb207 \\
\hline Author(s) & Nezu, Y ukio; Zhang, Yu-Qiao; Chen, Chunlin; Ikuhara, Y uichi; Ohta, Hiromichi \\
\hline Citation & $\begin{array}{l}\text { Journal of A pplied Physics, 122(13), } 135305 \\
\text { https://doi.org/10.1063/1.4997813 }\end{array}$ \\
\hline Issue Date & 2017-10-07 \\
\hline Doc URL & http:/hdl.handle.net/2115//1635 \\
\hline Rights & $\begin{array}{l}\text { The following article appeared in Y ukio Nezu, Y U-Qiao Zhang, Chunlin Chen, Y uichi Ikuhara and Hiromichi Ohta, } \\
\text { Solid-phase epitaxial film growth and optical properties of a ferroelectric oxide, Sr2Nb2O 7, Journal of A pplied Physics } \\
\text { 122, } 135305 \text { (2017), doi: } 10.1063 / 1.4997813 \text { and may be found at http://aip.scitation.org/doi/abs/10.1063/1.4997813. }\end{array}$ \\
\hline Type & article \\
\hline File Information & 1.4997813.pdf \\
\hline
\end{tabular}

Instructions for use 


\section{Solid-phase epitaxial film growth and optical properties of a ferroelectric oxide, $\mathrm{Sr}_{2} \mathrm{Nb}_{2} \mathrm{O}_{7}$}

Yukio Nezu, Yu-Qiao Zhang, Chunlin Chen, Yuichi Ikuhara, and Hiromichi Ohta

Citation: Journal of Applied Physics 122, 135305 (2017);

View online: https://doi.org/10.1063/1.4997813

View Table of Contents: http://aip.scitation.org/toc/jap/122/13

Published by the American Institute of Physics

\section{Articles you may be interested in}

Highly conducting leakage-free electrolyte for $\mathrm{SrCoO}_{\mathrm{X}}$-based non-volatile memory device

Journal of Applied Physics 122, 135303 (2017); 10.1063/1.5005520

Thermoelectric phase diagram of the $\mathrm{SrTiO}_{3}-\mathrm{SrNbO}_{3}$ solid solution system

Journal of Applied Physics 121, 185102 (2017); 10.1063/1.4983359

Kinetic pathway of the ferroelectric phase formation in doped $\mathrm{HfO}_{2}$ films

Journal of Applied Physics 122, 124104 (2017); 10.1063/1.5003918

Electric-field control of electronic transport properties and enhanced magnetoresistance in $\mathrm{La}_{0.7} \mathrm{Sr}_{0.3} \mathrm{MnO}_{3} / 0.5 \mathrm{BaZr}_{0.2} \mathrm{Ti}_{0.8} \mathrm{O}_{3}-0.5 \mathrm{Ba}_{0.7} \mathrm{Ca}_{0.3} \mathrm{TiO}_{3}$ lead-free multiferroic structures Journal of Applied Physics 122, 134102 (2017); 10.1063/1.4990513

Effect of Holmium substitution on the magnetic and magnetodielectric properties of multiferroic $\mathrm{Bi}_{2} \mathrm{Fe}_{4} \mathrm{O}_{9}$ Journal of Applied Physics 122, 134103 (2017); 10.1063/1.4994645

Chiral phase transition at $180^{\circ}$ domain walls in ferroelectric $\mathrm{PbTiO}_{3}$ driven by epitaxial compressive strains Journal of Applied Physics 122, 134104 (2017); 10.1063/1.5006607

\section{Scilight} Sharp, quick summaries illuminating the latest physics research

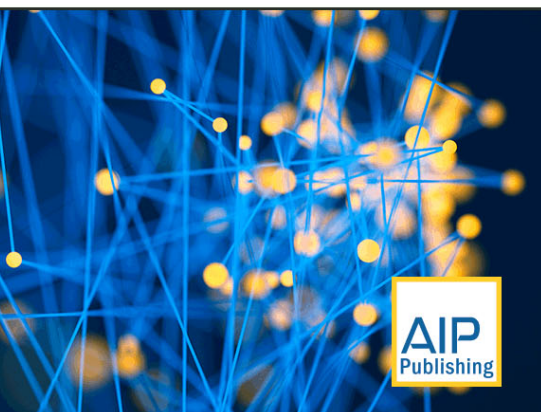




\title{
Solid-phase epitaxial film growth and optical properties of a ferroelectric oxide, $\mathrm{Sr}_{2} \mathrm{Nb}_{2} \mathrm{O}_{7}$
}

\author{
Yukio Nezu, ${ }^{1}$ Yu-Qiao Zhang, ${ }^{1}$ Chunlin Chen, ${ }^{2}$ Yuichi Ikuhara, ${ }^{2,3}$ and Hiromichi Ohta ${ }^{4, a)}$ \\ ${ }^{1}$ Graduate School of Information Science and Technology, Hokkaido University, N14W9, Kita, \\ Sapporo 060-0814, Japan \\ ${ }^{2}$ WPI Advanced Institute for Materials Research, Tohoku University, 2-1-1 Katahira, Aoba, \\ Sendai 980-8577, Japan \\ ${ }^{3}$ Institute of Engineering Innovation, The University of Tokyo, 2-11-16 Yayoi, Bunkyo, Tokyo 113-8656, Japan \\ ${ }^{4}$ Research Institute for Electronic Science, Hokkaido University, N20W10, Kita, Sapporo 001-0020, Japan
}

(Received 27 July 2017; accepted 19 September 2017; published online 4 October 2017)

High-quality epitaxial films of a ferroelectric oxide $\mathrm{Sr}_{2} \mathrm{Nb}_{2} \mathrm{O}_{7}$ were successfully fabricated by solid phase epitaxy (SPE) on (110) $\mathrm{LaAlO}_{3}$ single crystal substrates. In the SPE method, amorphous $\mathrm{Sr}-\mathrm{Nb}-\mathrm{O}$ films are first deposited by pulsed laser deposition at room temperature and then annealed in vacuum at elevated temperatures, resulting in the crystallization of $\mathrm{Sr}_{2} \mathrm{Nb}_{2} \mathrm{O}_{7}$ with highly ordered atomic arrangement and an atomically flat surface. The refractive index of the resultant film was 2.1, indicating that the dielectric permittivity of the film was in between 20 and 80, which corresponds well with that of single crystal $\mathrm{Sr}_{2} \mathrm{Nb}_{2} \mathrm{O}_{7}$, demonstrating the effectiveness of the SPE method for the fabrication of high-quality epitaxial films of $\mathrm{Sr}_{2} \mathrm{Nb}_{2} \mathrm{O}_{7}$. Published by AIP Publishing.

https://doi.org/10.1063/1.4997813

\section{INTRODUCTION}

Epitaxial films with highly ordered atomic arrangements and atomically flat surfaces are extremely important for experiments that aim to extract the fundamental physical properties of functional oxides, in particular, their optical and carrier transport properties, and the photochemical reactivity of their surfaces. Generally, vapor phase epitaxy (VPE) methods, such as pulsed laser deposition (PLD) ${ }^{1}$ and molecular beam epitaxy (MBE) ${ }^{2-5}$ are used to fabricate high-quality epitaxial oxide films at high temperatures $\left(\sim 1000^{\circ} \mathrm{C}\right)$. In addition to these VPE methods, the solid phase epitaxy (SPE) method, which involves high temperature crystallization of an amorphous precursor film, is particularly useful for the epitaxial growth of complex oxides with layered crystal structures. ${ }^{6}$ Since the melting point of complex oxides usually exceeds $2000^{\circ} \mathrm{C}$, a heating temperature of $T>1000^{\circ} \mathrm{C}$, which is $\sim 60 \%$ of the melting point, is required to achieve Frank-van der Merwe growth. ${ }^{7}$ When using VPE techniques, the chemical composition has proved to be very difficult to control if there is a difference in vapor pressure between the different constituents, as those with higher vapor pressures tend to reevaporate during the film deposition process. Furthermore, control over the degree of oxidation in the vapor phase has also been found to be challenging; on the other hand, the chemical composition can be easily controlled by SPE as the deposited amorphous precursor film is heated either in air or in a controlled atmosphere.

In this study, we focused on high-quality epitaxial film growth of a complex layered oxide, $\mathrm{Sr}_{2} \mathrm{Nb}_{2} \mathrm{O}_{7}$, which is one of the homologous phases in $\mathrm{Sr}_{n} \mathrm{Nb}_{n} \mathrm{O}_{3 n+2}$ phases. In this homologous phase, $n=4,5$, and $\infty$ have attracted extensive

\footnotetext{
a) Author to whom correspondence should be addressed: hiromichi.ohta@ es.hokudai.ac.jp
}

attention as active materials in applications such as ferroelectric insulators, ${ }^{8,9}$ thermoelectric materials, ${ }^{10,11}$ metals, ${ }^{12,13}$ and photocatalysts. ${ }^{14-16}$ Figure 1 presents schematic diagrams of the crystal structures of the homologous phases of $\mathrm{Sr}_{n} \mathrm{Nb}_{n} \mathrm{O}_{3 n+2}$ : although the $n=\infty$ phase $\mathrm{SrNbO}_{3}$ (space group Pm3m, $a=4.023 \AA$ ) crystallizes with a simple perovskite structure [Fig. 1(c)], the $n=4$ phase $\mathrm{Sr}_{2} \mathrm{Nb}_{2} \mathrm{O}_{7}$ (space group $C m c 21, a=3.933 \AA, b=26.726 \AA$, and $c=5.683 \AA$ ) and the $n=5$ phase $\mathrm{SrNbO}_{3.4}$ (space group Pnnm, $a=3.995 \AA, b=56.740 \AA$, and $c=32.456 \AA$ ) form layered structures composed of distorted (110) $\mathrm{SrNbO}_{3}$ slabs: in the $n=4$ phase, four distorted $\mathrm{SrNbO}_{3}$ slabs are stacked along the [010] direction [Fig. 1(a)]; for the $n=5$ phase, five distorted $\mathrm{SrNbO}_{3}$ slabs are stacked along the [001], as shown in [Fig. 1(b)]. The number of $\mathrm{SrNbO}_{3}$ slabs in the layered $\mathrm{Sr}_{n} \mathrm{Nb}_{n} \mathrm{O}_{3 n+2}$ structures depends on the degree of oxidationthe valence states of the $\mathrm{Nb}$ ions vary from structure to structure, with each containing different ratios of $\mathrm{Nb}^{5+}\left(\mathrm{Nb} 4 \mathrm{~d}^{0}\right)$ and $\mathrm{Nb}^{4+}\left(4 \mathrm{~d}^{1}\right): 100 \% \mathrm{Nb}^{5+}$ in $\mathrm{Sr}_{2} \mathrm{Nb}_{2} \mathrm{O}_{7} ; 80 \% \mathrm{Nb}^{5+} / 20 \%$ $\mathrm{Nb}^{4+}$ in $\mathrm{SrNbO}_{3.4}$; and $100 \% \mathrm{Nb}^{4+}$ in $\mathrm{SrNbO}_{3}$. Consequently, the electronic properties of these materials differ greatly: $\mathrm{Sr}_{2} \mathrm{Nb}_{2} \mathrm{O}_{7}$ is a wide-bandgap ferroelectric insulator $\left(E_{\mathrm{g}}\right.$ $=3.9 \mathrm{eV}), \mathrm{SrNbO}_{3.4}$ is a quasi-1D metal, ${ }^{17}$ and $\mathrm{SrNbO}_{3}$ is a metal. Interestingly, the $\mathrm{SrNbO}_{3.4}$ phase can be converted into $\mathrm{SrNbO}_{3}$ by irradiation with an electron beam in vacuum. ${ }^{18}$

At the time of writing, there are only two existing reports on the epitaxial growth of $\mathrm{Sr}_{2} \mathrm{Nb}_{2} \mathrm{O}_{7}$ films: in 1976, Ishitani and Kimura fabricated such films on single crystal (010) $\mathrm{Sr}_{2} \mathrm{Ta}_{2} \mathrm{O}_{7}$ substrates using an $\mathrm{RF}$ sputtering technique, ${ }^{19}$ while in 2008, Balasubramaniam et al. reported that (010)-oriented epitaxial $\mathrm{Sr}_{2} \mathrm{Nb}_{2} \mathrm{O}_{7}$ films could be grown on (110) $\mathrm{SrTiO}_{3}$ by PLD. ${ }^{20}$ Therefore, we first tried to fabricate epitaxial films of $\mathrm{Sr}_{2} \mathrm{Nb}_{2} \mathrm{O}_{7}$ on single crystal (110) $\mathrm{LaAlO}_{3}$ substrates by PLD at high temperatures $\left(\sim 900^{\circ} \mathrm{C}\right)$ under a range of different oxygen partial pressures $\left(10^{-4}-10^{1} \mathrm{~Pa}\right)$. 

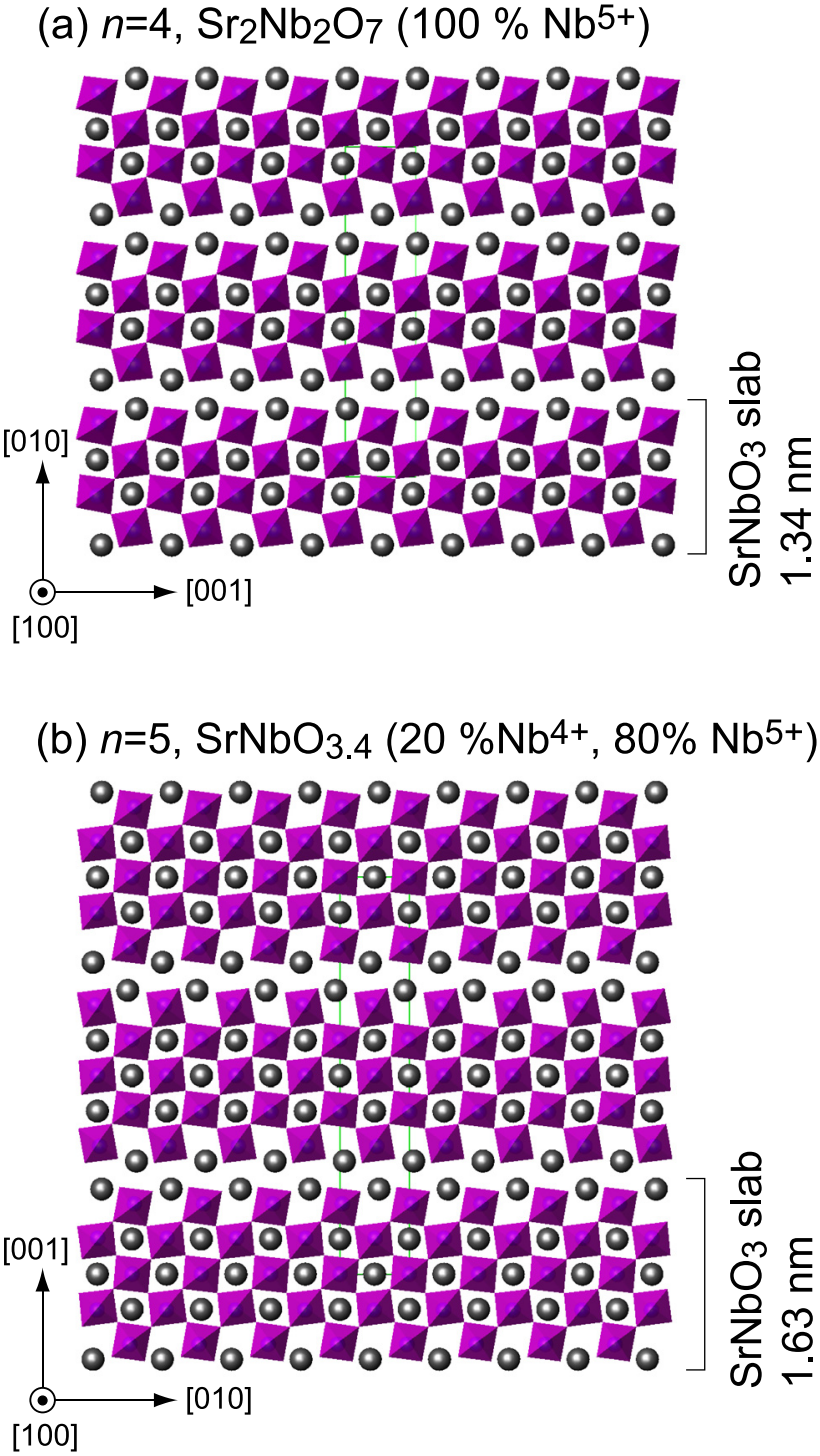

(c) $n=\infty, \mathrm{SrNbO}_{3}\left(100 \% \mathrm{Nb}^{4+}\right)$

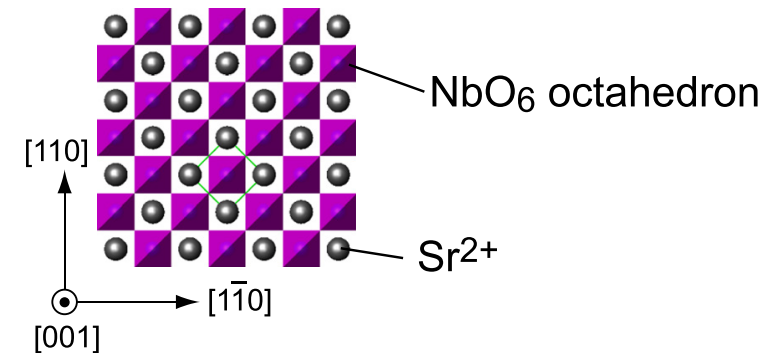

FIG. 1. Schematic crystal structures of homologous phases of $\mathrm{Sr}_{n} \mathrm{Nb}_{n} \mathrm{O}_{3 n+2}$. (a) $n=4$ (ferroelectric insulator, $\mathrm{Sr}_{2} \mathrm{Nb}_{2} \mathrm{O}_{7}$, space group Cmc21), (b) $n=5$ (quasi-1D metal, $\mathrm{SrNbO}_{3.4}$, space group Pnnm), and (c) $n=\infty$ (metal, $\mathrm{SrNbO}_{3}$, space group $\left.\mathrm{Pm} 3 m\right)$.

However, we were not able to successfully deposit the desired epitaxial films (data not shown), and the films synthesized using these conditions were composed of two phases, (001)oriented $\mathrm{Sr}_{2} \mathrm{Nb}_{2} \mathrm{O}_{7}$ and (110)-oriented $\mathrm{SrNbO}_{3}$. The epitaxial relationships between the films and the substrate were (001) [100] $\mathrm{Sr}_{2} \mathrm{Nb}_{2} \mathrm{O}_{7} \|(110)$ [001] $\mathrm{LaAlO}_{3}$ and (110)[001] $\mathrm{SrNbO}_{3} \|$ (110)[001] $\mathrm{LaAlO}_{3}$, respectively. The film surfaces were composed of irregularly shaped grains with diameters of $<100 \mathrm{~nm}$, as observed by atomic force microscopy (AFM), similar to those reported by Balasubramaniam et al. ${ }^{20}$

Rather than continuing with this technique, we opted to seek an alternative synthetic route, deciding to proceed using SPE. Here, amorphous Sr-Nb-O films, deposited by PLD at room temperature, were heated at high temperatures. We expected that the most stable phase, $\mathrm{Sr}_{2} \mathrm{Nb}_{2} \mathrm{O}_{7}$, would crystallize directly during the heat treatment, without forming the $\mathrm{SrNbO}_{3}$ phase. From the results of this experiment, we confirm that high-quality epitaxial films of $\mathrm{Sr}_{2} \mathrm{Nb}_{2} \mathrm{O}_{7}$ can be successfully grown by SPE, possessing both the highly ordered atomic arrangements and flat surfaces. The refractive index of the resultant film was 2.1, indicating that the dielectric permittivity of the film was in between 20 and 80, which corresponds well with that of the single crystals.

\section{EXPERIMENTAL}

$\mathrm{Sr}_{2} \mathrm{Nb}_{2} \mathrm{O}_{7}$ films were fabricated by the SPE technique on a (110)-oriented $\mathrm{LaAlO}_{3}$ single crystal substrate. First, amorphous $\mathrm{Sr}-\mathrm{Nb}-\mathrm{O}$ films were deposited by PLD at room temperature, using a $\mathrm{KrF}$ excimer laser $(\lambda=248 \mathrm{~nm}, 20 \mathrm{~ns}$ pulse width, Coherent COMPex Pro 102) to ablate the dense, ceramic target disk consisting of $\mathrm{Sr}_{2} \mathrm{Nb}_{2} \mathrm{O}_{7}$. The laser fluence, repetition rate, and deposition rate were $\sim 1 \mathrm{~J} \mathrm{~cm}^{-2}$ pulse $\mathrm{s}^{-1}, 1 \mathrm{~Hz}$, and $\sim 17 \mathrm{pm}$ pulse ${ }^{-1}$, respectively. Then, the deposited films were heated at $1400{ }^{\circ} \mathrm{C}$ in a tube furnace, which was evacuated during heating by a rotary pump.

The crystallographic orientations of the resultant films were analyzed by high-resolution X-ray diffraction (XRD, ATX-G, Rigaku), using monochromated $\mathrm{Cu} \mathrm{K} \alpha_{1}$ radiation $(\lambda=1.54059 \AA)$. The surface morphology of the resultant films was observed by AFM (Nanocute, Hitachi High-Tech). Analysis of the cross-sectional microstructure and atomic arrangement of the films was conducted by transmission electron microscopy (TEM) and scanning transmission electron microscopy (STEM). Thin-foil specimens for TEM and STEM imaging were prepared using a standard Ar ion-beam thinning process, with an accelerating gun voltage in the range of $1-4 \mathrm{kV}$. Bright-field TEM images were taken at $200 \mathrm{kV}$ using a JEM-2010F (JEOL) microscope, and highangle annular dark-field (HAADF) images were obtained using a $200 \mathrm{kV}$ STEM (ARM200FC, JEOL) equipped with a probe corrector (CEOS Gmbh).

The optical transmission and reflection spectra were measured using a UV-VIS-NIR spectrometer (SolidSpec3700 , Shimadzu) at room temperature.

\section{RESULTS AND DISCUSSION}

Figure 2 summarizes XRD patterns of these resultant films grown by the SPE method. Only intense diffraction peaks of (0k0) ( $k=$ even) $\mathrm{Sr}_{2} \mathrm{Nb}_{2} \mathrm{O}_{7}$ were seen in the out-ofplane Bragg diffraction pattern [Fig. 2(a)], together with the 110 peaks from the $\mathrm{LaAlO}_{3}$ substrate. The average crystal tilting of $\mathrm{Sr}_{2} \mathrm{Nb}_{2} \mathrm{O}_{7}$ was $\sim 0.1^{\circ}$, which was evaluated by measuring the out-of-plane X-ray rocking curve of the (080) diffraction peak, as shown in the inset of Fig. 2(a): this indicated that the film was strongly orientated in the $b$-axis. 

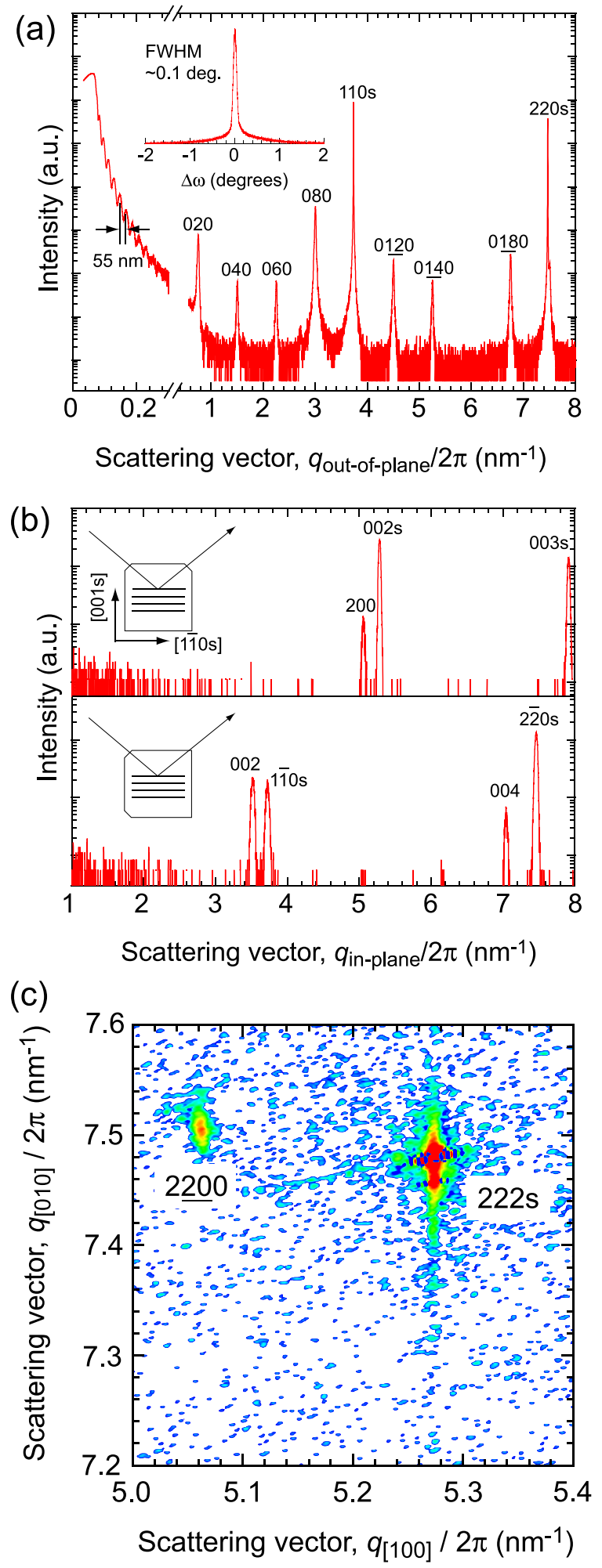

FIG. 2. X-ray diffraction analyses of a $\mathrm{Sr}_{2} \mathrm{Nb}_{2} \mathrm{O}_{7}$ film grown by the solid phase epitaxy method on a (110) $\mathrm{LaAlO}_{3}$ substrate. (a) Out-of-plane Bragg diffraction patterns. The peaks associated with the (110) $\mathrm{LaAlO}_{3}$ substrate are appended with "s." Kiessig fringes observed at lower $q_{\text {out-of-plane }} / 2 \pi$ $\left(\sim 0.2 \mathrm{~nm}^{-1}\right)$ were used to calculate the film's thickness, yielding a value of $55 \mathrm{~nm}$. The inset shows an out-of-plane $\mathrm{X}$-ray rocking curve acquired around the (080) $\mathrm{Sr}_{2} \mathrm{Nb}_{2} \mathrm{O}_{7}$ peak. (b) In-plane X-ray Bragg diffraction patterns (upper: azimuth $\langle 001\rangle \mathrm{LaAlO}_{3}$; lower: (110) $\mathrm{LaAlO}_{3}$ ). The epitaxial relationship between the film and the substrate was found to be (010)[100] $\mathrm{Sr}_{2} \mathrm{Nb}_{2} \mathrm{O}_{7} \|(110)[001] \mathrm{LaAlO}_{3}$. (c) X-ray reciprocal space mapping around the (222) diffraction spot from $\mathrm{LaAlO}_{3}$. The intense 2200 diffraction spot originated from $\mathrm{Sr}_{2} \mathrm{Nb}_{2} \mathrm{O}_{7}$, while the spot labeled 222s originated from the $\mathrm{LaAlO}_{3}$ substrate.
Kiessig fringes ${ }^{21}$ are clearly seen at lower values of $q_{\text {out-of-planel }}$ $2 \pi$, indicating that these films possessed smooth surfaces; additionally, the film thickness was estimated to be $\sim 55 \mathrm{~nm}$, calculated from the fringes around $\sim 0.2 \mathrm{~nm}^{-1}$.

Two-fold symmetry was clearly observed in the in-plane $\mathrm{X}$-ray Bragg diffraction patterns in Fig. 2(b). In the upper figure (azimuth [001] $\mathrm{LaAlO}_{3}$ ), the $200 \mathrm{Sr}_{2} \mathrm{Nb}_{2} \mathrm{O}_{7}$ diffraction peak was seen alongside the $002 \mathrm{LaAlO}_{3}$ substrate peak, whereas in the lower figure ([110] $\left.\mathrm{LaAlO}_{3}\right)$, the diffraction peaks from the $00 l(l=$ even $)$ were observed. The epitaxial relationship between the film and the substrate was found to be (010)[100] $\mathrm{Sr}_{2} \mathrm{Nb}_{2} \mathrm{O}_{7} \|(110)[001] \mathrm{LaAlO}_{3}$. Furthermore, we recorded the reciprocal space mappings of the resultant films around the $\mathrm{LaAlO}_{3} 222$ diffraction spots [Fig. 2(c)]. Intense 2200 diffraction spots were seen at $\left(q_{[100]} / 2 \pi, q_{[010]} /\right.$ $\left.2 \pi=5.06 \mathrm{~nm}^{-1}, 7.51 \mathrm{~nm}^{-1}\right)$ together with the $222 \mathrm{LaAlO}_{3}$ $\left(5.27 \mathrm{~nm}^{-1}, 7.48 \mathrm{~nm}^{-1}\right)$, clearly demonstrating that incoherent epitaxial growth had occurred in these films. The lateral grain size of the $\mathrm{Sr}_{2} \mathrm{Nb}_{2} \mathrm{O}_{7}$ film was calculated to exceed $500 \mathrm{~nm}$, although a precise calculation was not possible due to the resolution limitations of the technique.

The surface morphology of the films was observed using AFM, with RHEED patterns also used for complementary surface analysis. Figure 3(a) shows a typical topographic AFM image $\left(2 \times 2 \mu \mathrm{m}^{2}\right)$ of a $\mathrm{Sr}_{2} \mathrm{Nb}_{2} \mathrm{O}_{7}$ film deposited by SPE. Large, hexagonally shaped grains with a stepped surface structure were observed, with step increments of $\sim 1.3 \mathrm{~nm}$, which corresponds well with the value of half of the $b$-axis length for $\mathrm{Sr}_{2} \mathrm{Nb}_{2} \mathrm{O}_{7}(b / 2=1.34 \mathrm{~nm}$ ) (data not shown). Intense diffraction spots were seen in the RHEED patterns shown in Fig. 3(b), indicating that the surface of each grain was atomically flat and that the grains were of high crystal quality.

Figure 4(a) shows cross-sectional bright-field TEM images of the SPE-derived $\mathrm{Sr}_{2} \mathrm{Nb}_{2} \mathrm{O}_{7}$ films, acquired using an incident electron beam direction of [001] $\mathrm{Sr}_{2} \mathrm{Nb}_{2} \mathrm{O}_{7}$ ( $\equiv[110] \mathrm{LaAlO}_{3}$ ). Here, the topmost part of the film was observed to be atomically flat, and the film thickness was
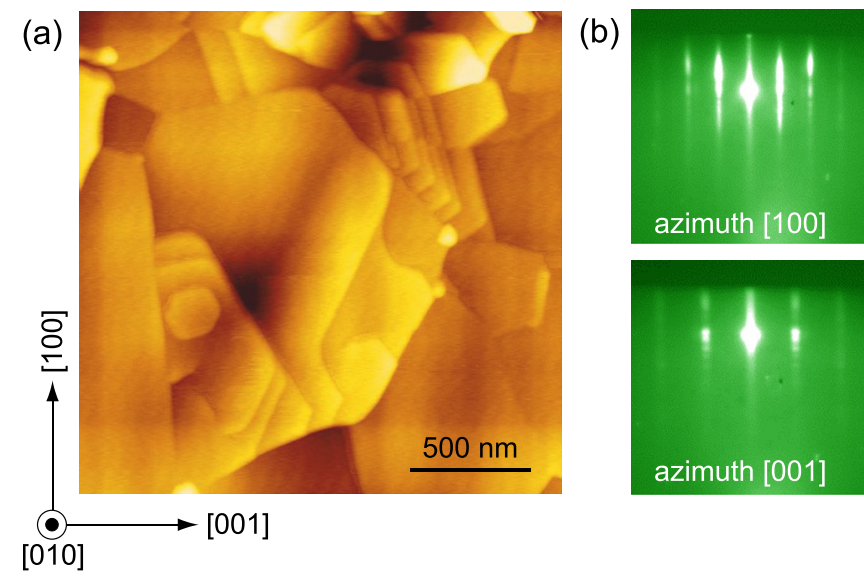

FIG. 3. Surface characterization of a $\mathrm{Sr}_{2} \mathrm{Nb}_{2} \mathrm{O}_{7}$ film grown by the solid phase epitaxy method on a (110) $\mathrm{LaAlO}_{3}$ substrate. (a) Topographic AFM image $\left(2 \times 2 \mu \mathrm{m}^{2}\right)$. The step increments in the surface structure were estimated to be $\sim 1.3 \mathrm{~nm}$. (b) RHEED patterns (upper: azimuth [100] $\mathrm{Sr}_{2} \mathrm{Nb}_{2} \mathrm{O}_{7}$; lower: azimuth [001] $\mathrm{Sr}_{2} \mathrm{Nb}_{2} \mathrm{O}_{7}$ ). Kikuchi lines are observed alongside the diffraction spots in both cases. 


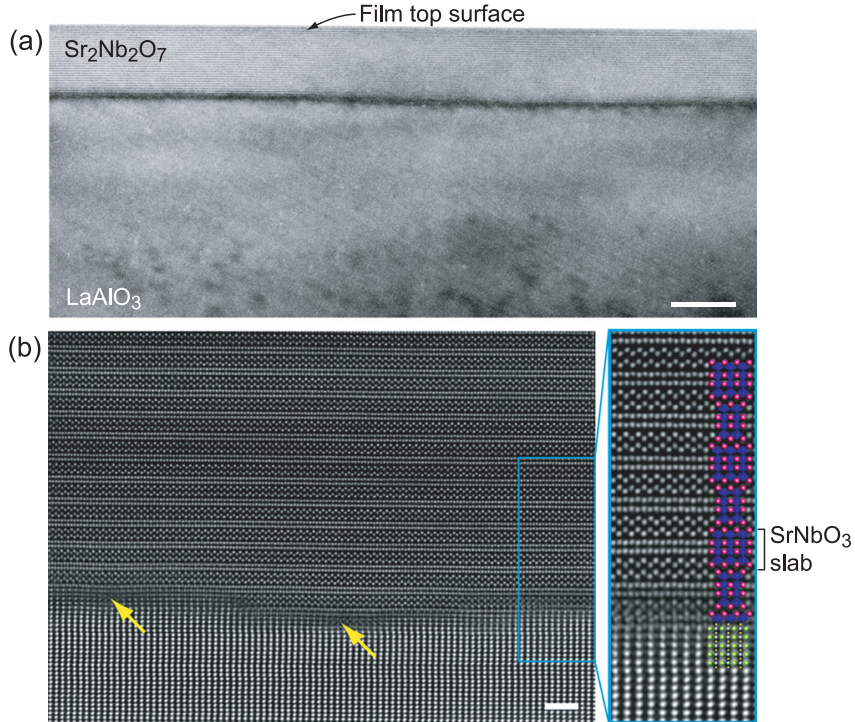

FIG. 4. Atomic arrangement of a $\mathrm{Sr}_{2} \mathrm{Nb}_{2} \mathrm{O}_{7}$ film grown by solid phase epitaxy method on a (110) $\mathrm{LaAlO}_{3}$ substrate. (a) Cross-sectional bright-field TEM image acquired with an incident electron beam direction along the [010] $\mathrm{Sr}_{2} \mathrm{Nb}_{2} \mathrm{O}_{7}$ (三 [110] $\mathrm{LaAlO}_{3}$ ). The scale bar is $50 \mathrm{~nm}$. The film thickness was measured to be $\sim 55 \mathrm{~nm}$; (b) HAADF-STEM image (scale $b a r=2 \mathrm{~nm}$ ). The magnified image focuses on the periodic layered structure, with a calculated distance of $1.3 \mathrm{~nm}$ between $\mathrm{SrNbO}_{3}$ slabs. Interfacial steps and misfit dislocations (indicated by the yellow arrows) are seen in the heterointerfacial region. found to be $\sim 55 \mathrm{~nm}$, a value that corresponds closely to those calculated from the XRD results. Many stripes were seen in the film, indicating that the (110) $\mathrm{SrNbO}_{3}$ slabs were stacked along the $b$-axis. A darker layer with a thickness of a few nanometers was observed at the heterointerface; in order to clarify the origin of this layer, we collected data on the atomic arrangements around the heterointerface using HAADF-STEM, with a collection semi-angle of 68-280 mrad-these results are shown in Fig. 4(b). Interfacial steps and misfit dislocations (indicated by the yellow arrows) were seen around the heterointerface, which were considered to lead to the presence of stress concentration at the interface and the dark contrast seen in Fig. 4(a). In the region above the interface, a highly ordered, periodic layered structure with $\mathrm{SrNbO}_{3}$ slabs located every $1.3 \mathrm{~nm}$ can clearly be observed. From these results, we concluded that the resultant $\mathrm{Sr}_{2} \mathrm{Nb}_{2} \mathrm{O}_{7}$ films were enough to discuss its intrinsic physical properties.

In order to compare the physical properties of the resultant $\mathrm{Sr}_{2} \mathrm{Nb}_{2} \mathrm{O}_{7}$ films with those of $\mathrm{Sr}_{2} \mathrm{Nb}_{2} \mathrm{O}_{7}$ single crystals, ${ }^{8}$ we measured optical properties including transmission $(T)$, reflection $(R)$, and absorption (Abs.) spectra at room temperature. Figure 5(a) shows $\mathrm{T}, \mathrm{R}$, and Abs. spectra of a $\mathrm{Sr}_{2} \mathrm{Nb}_{2} \mathrm{O}_{7}$ film (Thickness: $60 \mathrm{~nm}$ ). The absorption edge is $\sim 320 \mathrm{~nm}$, indicating that the direct bandgap of the film is $3.9 \mathrm{eV}$. In the whole wavelength region, $R$ exceeds $20 \%$,
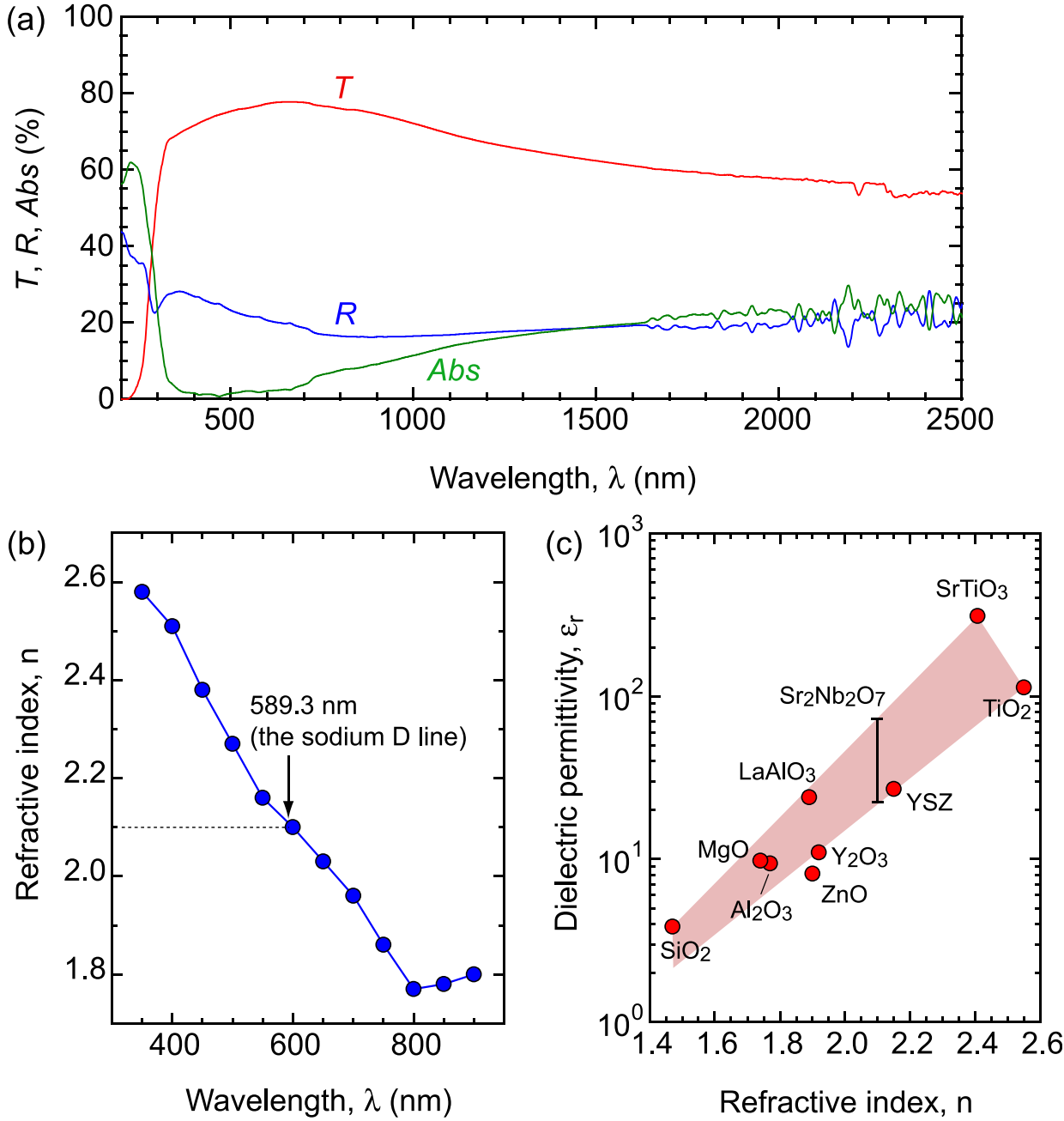

FIG. 5. Optical properties of a $\mathrm{Sr}_{2} \mathrm{Nb}_{2} \mathrm{O}_{7}$ film grown by the solid phase epitaxy method on a (110) $\mathrm{LaAlO}_{3}$ substrate. (a) Transmission $(T)$, reflection $(R)$, and absorption (Abs.) spectrum at room temperature. (b) Wavelength dependence of the refractive index (n) of the $\mathrm{Sr}_{2} \mathrm{Nb}_{2} \mathrm{O}_{7}$ film. The $\mathrm{n}$ at $589.3 \mathrm{~nm}$ (the sodium $\mathrm{D}$ line) is 2.1. (c) Relationship between dielectric permittivity at dc limit $\left(\varepsilon_{\mathrm{r}}\right)$ and $\mathrm{n}$ for the several dielectric oxides. The $\varepsilon_{\mathrm{r}}$ of the film was in between 20 and 80 , which corresponds well with that of the single crystals. 
indicating the large refractive index $(n)$ of the film. In fact, we obtained rather large $n=2.1$ at $589.3 \mathrm{~nm}$ (the sodium D line) from the $R$ spectrum [Fig. 5(b)]. We then speculated the dielectric permittivity at dc limit $\left(\varepsilon_{\mathrm{r}}\right)$ of the $\mathrm{Sr}_{2} \mathrm{Nb}_{2} \mathrm{O}_{7}$ film. Figure 5(c) shows the relationship between $\varepsilon_{\mathrm{r}}$ and $n$ of several dielectric oxides. The $\varepsilon_{\mathrm{r}}$ of the film was speculated to be in between 20 and 80 , comparable to that of the single crystal $\left(\varepsilon_{\mathrm{r} a}=75, \varepsilon_{\mathrm{r} b}=46\right.$, and $\left.\varepsilon_{\mathrm{rc}}=43\right) .^{8}$ These optical properties clearly indicate that the resultant $\mathrm{Sr}_{2} \mathrm{Nb}_{2} \mathrm{O}_{7}$ films are enough high quality to discuss its intrinsic physical properties.

Finally, we discuss the differences between direct VPE and SPE in the formation of $\mathrm{Sr}_{2} \mathrm{Nb}_{2} \mathrm{O}_{7}$ on (110) $\mathrm{LaAlO}_{3}$ substrates. In the case of VPE (PLD), both (001)-oriented $\mathrm{Sr}_{2} \mathrm{Nb}_{2} \mathrm{O}_{7}$ and (110)-oriented $\mathrm{SrNbO}_{3}$ phases formed, and the epitaxial relationship between the $\mathrm{Sr}_{2} \mathrm{Nb}_{2} \mathrm{O}_{7}$ film and the substrate was (001)[100] $\mathrm{Sr}_{2} \mathrm{Nb}_{2} \mathrm{O}_{7} \|(110)[001] \mathrm{LaAlO}_{3}$, in which the $\mathrm{SrNbO}_{3}$ slabs were stacked along the in-plane direction. We consider that the formation of perovskite $\mathrm{SrNbO}_{3}$ is more favorable in comparison to $\mathrm{Sr}_{2} \mathrm{Nb}_{2} \mathrm{O}_{7}$ during VPE, due to the insufficient oxidation of the material in the vapor phase. The formation of perovskite $\mathrm{SrNbO}_{3}$ domains may lead to a decrease in the degrees of freedom of the direction of crystal growth in neighboring $\mathrm{Sr}_{2} \mathrm{Nb}_{2} \mathrm{O}_{7}$ domains; (110) $\mathrm{SrNbO}_{3}$ slabs were not found to be stacked in the out-of-plane direction due to the differences in the out-of-plane atomic arrangement between $\mathrm{Sr}_{2} \mathrm{Nb}_{2} \mathrm{O}_{7}$ and $\mathrm{SrNbO}_{3}$. Therefore, when depositing the films by PLD, the (110) $\mathrm{SrNbO}_{3}$ slabs were stacked along the in-plane direction; on the other hand, in the case of SPE, $\mathrm{Sr}_{2} \mathrm{Nb}_{2} \mathrm{O}_{7}$ was able to crystallize directly from the amorphous state into the structure with the most stable epitaxial relationship.

\section{SUMMARY}

In summary, high-quality epitaxial films of $\mathrm{Sr}_{2} \mathrm{Nb}_{2} \mathrm{O}_{7}$ were successfully fabricated by solid phase epitaxy on (110) $\mathrm{LaAlO}_{3}$ single crystal substrates. Amorphous $\mathrm{Sr}-\mathrm{Nb}-\mathrm{O}$ films, deposited by PLD at room temperature, crystallized epitaxially as $\mathrm{Sr}_{2} \mathrm{Nb}_{2} \mathrm{O}_{7}$ films at a high temperature of $1400^{\circ} \mathrm{C}$, resulting in the formation of a highly ordered atomic arrangement and an atomically flat surface. The epitaxial relationship between the film and the substrate was (010)[100] $\mathrm{Sr}_{2} \mathrm{Nb}_{2} \mathrm{O}_{7} \|(110)[001] \mathrm{LaAlO}_{3}$. The refractive index of the resultant film was 2.1, indicating that the dielectric permittivity of the film was in between 20 and 80, which corresponds well with that of the single crystals. These results clearly demonstrate the effectiveness of the SPE method for the fabrication of high-quality epitaxial films of $\mathrm{Sr}_{2} \mathrm{Nb}_{2} \mathrm{O}_{7}$.

\section{ACKNOWLEDGMENTS}

This research was supported by Grants-in-Aid for Scientific Research on Innovative Areas "Nano Informatics" (25106005, 25106007) from the Japan Society for the Promotion of Science (JSPS). H.O. was supported by Grants-in-Aid for Scientific Research A (17H01314) and
B (26287064) from JSPS. Y.Z. thanks China Scholarship Council (CSC) for a scholarship to study in Japan.

${ }^{1}$ Pulsed Laser Deposition of Thin Films: Applications-Led Growth of Functional Materials, edited by R. Eason (Wiley-Interscience, 2006).

${ }^{2}$ A. Tsukazaki, S. Akasaka, K. Nakahara, Y. Ohno, H. Ohno, D. Maryenko, A. Ohtomo, and M. Kawasaki, "Observation of the fractional quantum Hall effect in an oxide," Nat. Mater. 9, 889 (2010).

${ }^{3}$ J. Son, P. Moetakef, B. Jalan, O. Bierwagen, N. J. Wright, R. EngelHerbert, and S. Stemmer, "Epitaxial $\mathrm{SrTiO}_{3}$ films with electron mobilities exceeding 30,000 $\mathrm{cm}^{2} \mathrm{~V}^{-1} \mathrm{~s}^{-1}$," Nat. Mater. 9, 482 (2010).

${ }^{4}$ W. Tian, J. H. Haeni, D. G. Schlom, E. Hutchinson, B. L. Sheu, M. M. Rosario, P. Schiffer, Y. Liu, M. A. Zurbuchen, and X. Q. Pan, "Epitaxial growth and magnetic properties of the first five members of the layered $\mathrm{Sr}_{\mathrm{n}+1} \mathrm{Ru}_{\mathrm{n}} \mathrm{O}_{3 \mathrm{n}+1}$ oxide series," Appl. Phys. Lett. 90, 022507 (2007).

${ }^{5}$ J. H. Haeni, C. D. Theis, D. G. Schlom, W. Tian, X. Q. Pan, H. Chang, I. Takeuchi, and X. D. Xiang, "Epitaxial growth of the first five members of the $\mathrm{Sr}_{\mathrm{n}+1} \mathrm{Ti}_{\mathrm{n}} \mathrm{O}_{3 \mathrm{n}+1}$ Ruddlesden-Popper homologous series," Appl. Phys. Lett. 78, 3292 (2001).

${ }^{6}$ H. Ohta, K. Nomura, M. Orita, M. Hirano, K. Ueda, T. Suzuki, Y. Ikuhara, and $\mathrm{H}$. Hosono, "Single-crystalline films of the homologous series $\mathrm{InGaO}_{3}(\mathrm{ZnO})_{\mathrm{m}}$ grown by reactive solid-phase epitaxy," Adv. Funct. Mater. 13, 139 (2003).

${ }^{7}$ Current Topics in Materials Science, edited by E. Kaldis (Elsevier Science Ltd, 1980).

${ }^{8}$ S. Nanamatsu, M. Kimura, K. Doi, and M. Takahashi, "Ferroelectric properties of $\mathrm{Sr}_{2} \mathrm{Nb}_{2} \mathrm{O}_{7}$ single crystal, ” J. Phys. Soc. Jpn. 30, 300 (1971).

${ }^{9}$ Y. Fujimori, N. Izumi, T. Nakamura, and A. Kamisawa, "Application of $\mathrm{Sr}_{2} \mathrm{Nb}_{2} \mathrm{O}_{7}$ family ferroelectric films for ferroelectric memory field effect transistor," Jpn. J. Appl. Phys., Part 1 37, 5207 (1998).

${ }^{10}$ A. Sakai, T. Kanno, K. Takahashi, Y. Yamada, and H. Adachi, "Large anisotropic thermoelectricity in perovskite related layered structure: $\mathrm{Sr}_{n} \mathrm{Nb}_{n} \mathrm{O}_{3 n+2}(n=4,5)$, , J. Appl. Phys. 108, 103706 (2010).

${ }^{11}$ W. Kobayashi, Y. Hayashi, M. Matsushita, Y. Yamamoto, I. Terasaki, A. Nakao, H. Nakao, Y. Murakami, Y. Moritomo, H. Yamauchi, and M. Karppinen, "Anisotropic thermoelectric properties associated with dimensional crossover in quasi-one-dimensional $\mathrm{SrNbO}_{3.4+\mathrm{d}}(\mathrm{d} \approx 0.03)$," Phys. Rev. B 84, 085118 (2011).

${ }^{12}$ T. Tomio, H. Miki, H. Tabata, T. Kawai, and S. Kawai, "Control of electrical-conductivity in laser-deposited $\mathrm{SrTiO}_{3}$ thin-films with $\mathrm{Nb}$ doping," J. Appl. Phys. 76, 5886 (1994).

${ }^{13}$ D. Oka, Y. Hirose, S. Nakao, T. Fukumura, and T. Hasegawa, "Intrinsic high electrical conductivity of stoichiometric $\mathrm{SrNbO}_{3}$ epitaxial thin films," Phys. Rev. B 92, 205102 (2015).

${ }^{14}$ X. X. Xu, C. Randorn, P. Efstathiou, and J. T. S. Irvine, "A red metallic oxide photocatalyst," Nat. Mater. 11, 595 (2012).

${ }^{15}$ A. Kudo, H. Kato, and S. Nakagawa, "Water splitting into $\mathrm{H}_{2}$ and $\mathrm{O}_{2}$ on new $\mathrm{Sr}_{2} \mathrm{M}_{2} \mathrm{O}_{7}(\mathrm{M}=\mathrm{Nb}$ and $\mathrm{Ta})$ photocatalysts with layered perovskite structures: Factors affecting the photocatalytic activity," J. Phys. Chem. B 104, 571 (2000).

${ }^{16}$ Y. T. Zhu, Y. Dai, K. R. Lai, Z. J. Li, and B. B. Huang, "Optical transition and photocatalytic performance of $\mathrm{d}^{1}$ metallic perovskites," J. Phys. Chem. C 117, 5593 (2013).

${ }^{17}$ C. A. Kuntscher, S. Schuppler, P. Haas, B. Gorshunov, M. Dressel, M. Grioni, F. Lichtenberg, A. Herrnberger, F. Mayr, and J. Mannhart, "Extremely small energy gap in the quasi-one-dimensional conducting chain compound $\mathrm{SrNbO}_{3.41}$," Phys. Rev. Lett. 89, 236403 (2002).

${ }^{18}$ C. L. Chen, Z. C. Wang, F. Lichtenberg, Y. Ikuhara, and J. G. Bednorz, "Patterning oxide nanopillars at the atomic scale by phase transformation," Nano Lett. 15, 6469 (2015).

${ }^{19}$ A. Ishitani and M. Kimura, "Single-crystal $\mathrm{Sr}_{2} \mathrm{Nb}_{2} \mathrm{O}_{7}$ film opticalwaveguide deposited by Rf sputtering," Appl. Phys. Lett. 29, 289 (1976).

${ }^{20}$ K. R. Balasubramaniam, Y. Cao, N. Patel, S. Havelia, P. J. Cox, E. C. Devlin, E. P. Yu, B. J. Close, P. M. Woodward, and P. A. Salvador, "Phase and structural characterization of $\mathrm{Sr}_{2} \mathrm{Nb}_{2} \mathrm{O}_{7}$ and $\mathrm{SrNbO}_{3}$ thin films grown via pulsed laser ablation in $\mathrm{O}_{2}$ or $\mathrm{N}_{2}$ atmospheres," J. Solid State Chem. 181, 705 (2008).

${ }^{21}$ H. Kiessig, "Interference of X-rays in thick layers," Ann. Phys. 10, 769 (1931). 